\title{
On the Transfer of Leading Edge Serrations from Isolated Aerofoil to Ducted Low-Pressure Fan Application
}

\author{
Till M. Biedermann ${ }^{1 *}$ Nils Hintzen ${ }^{2}$ and Frank Kameier ${ }^{3}$ \\ University of Applied Sciences Duesseldorf, Duesseldorf, D-40474, Germany \\ T.P. Chong ${ }^{4}$ \\ Brunel University London, London UB83PH, UK \\ and \\ C. O. Paschereit ${ }^{5}$ \\ Berlin Technical University, Berlin, D-10623, Germany
}

\begin{abstract}
At high-turbulent inflow conditions, the blades of axial fans are known to emit a significantly increased amount of leading edge broadband noise. Recent research has firmly confirmed leading edge serrations to be an effective passive treatment in noise reduction. Up to now, leading edge serrations are mainly analysed in rigid test settings. With the aim of transferring leading edge serrations from the single aerofoil approach to the full rotor, an experimental rig was developed where a ducted low-pressure fan is installed. The fan blades are designed according to NACA65(12)-10 profiles, which were already analysed extensively in previous experimental and numerical studies. The rig allows to gather the aerodynamic and aeroacoustic data. Altogether, five different parameters can be analysed, namely the serration amplitude and wavelength, the stagger angle, the inflow turbulence and the rotational speed. The presented work focuses on a quantitative aerodynamic and aeroacoustic analysis of the designed rotor, where straight leading edges are compared to five sets of serrated blades, covering the full fan performance characteristics. A clear aeroacoustic sensitivity towards different incoming turbulence intensities was detected where a noise reduction can be observed especially for high serration amplitudes and large wavelengths. The aerodynamic performance primary scales with the ratio of serration wavelength and amplitude.
\end{abstract}

\section{Nomenclature}

$=$ serration amplitude $[\mathrm{mm}]$

$=$ constant, controlling growth rate [--]

$=$ aerofoil chord length [mm]

$=$ coefficient of lift [--]

$=$ coefficient of drag [-- $]$

$=$ bar diameter of turbulence grid $[\mathrm{mm}]$

$=$ duct diameter $[\mathrm{m}]$

$=$ turbulence grid of specific dimensions [--]

$=$ spectral correction of high-frequency dilution [--]

$=$ mesh width of turbulence grid [mm]

$=$ rotational frequency $\left[\mathrm{min}^{-1}\right]$

\footnotetext{
${ }^{1}$ Doctoral Researcher, Institute of Sound and Vibration Engineering ISAVE, till.biedermann@hs-duesseldorf.de, AIAA Student Member.

${ }^{2}$ Student, Institute of Sound and Vibration Engineering ISAVE.

${ }^{3}$ Professor, Institute of Sound and Vibration Engineering ISAVE.

${ }^{4}$ Senior Lecturer, Department of Mechanical, Aerospace and Civil Engineering, AIAA Member.

${ }^{5}$ Professor, Institute of Fluid Dynamics and Technical Acoustics ISTA.
}

American Institute of Aeronautics and Astronautics 


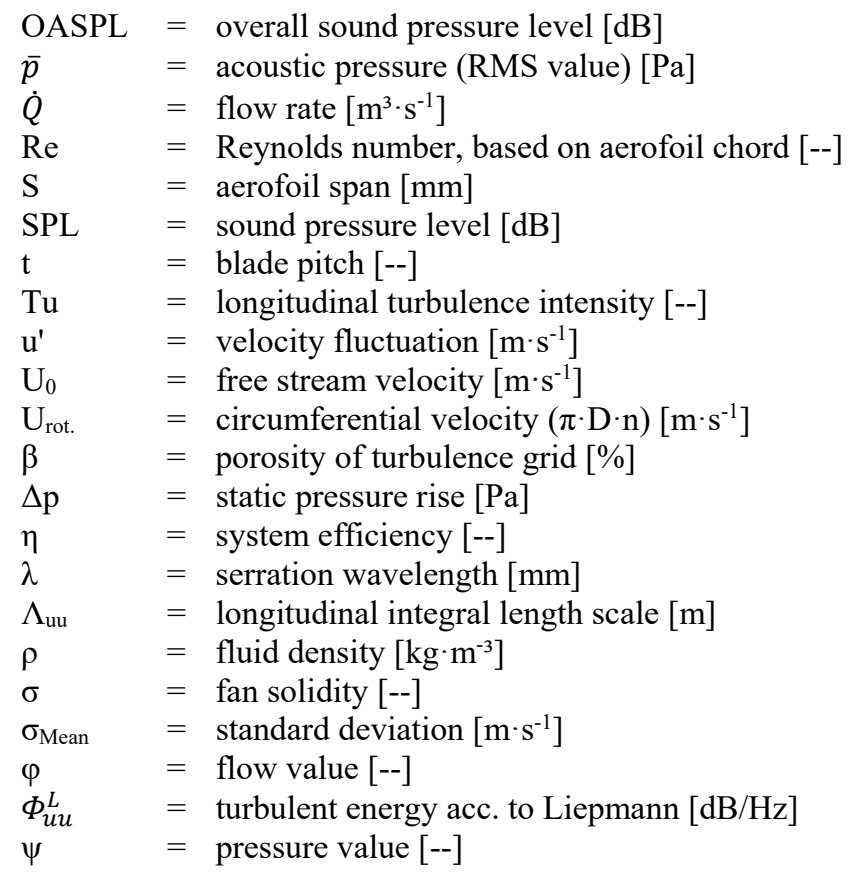

\section{Introduction}

$\mathrm{D}$

ISTORTED inflow conditions and significantly elevated turbulence upstream of a rotor or aerofoil are often observed where the noise radiation is dominated by broadband leading edge noise due to the impingement of turbulent structures on solid surfaces. In this context, leading edge serrations were found to be an effective passive treatment in both, noise reduction and in increasing specific parameters of the aerodynamic performance such as a delayed stall and high post-stall performance ${ }^{1-4}$. Up to now, leading edge serrations are mainly analysed in wind tunnel experiments where rigidly mounted aerofoils are tested. In preliminary studies Biedermann et al. analysed a NACA65(12)-10 aerofoil with and without sinusoidal leading edge serrations both, aeroacoustically and aerodynamically by use of experimental and numerical approaches ${ }^{5 ; 6 ; 2}$. A statistical-empirical model was developed to predict the broadband noise emissions by taking into account the chord based Reynolds number, the incoming turbulence intensity, the angle of attack as well as the serration parameters amplitude and wavelength. A clear ranking of the main influencing factors could be shown and, moreover, significant interdependencies between the influencing parameters could be detected as well. The Reynolds number (Re) and the freestream turbulence intensity (Tu) are identified to be the main contributors to the broadband noise emissions. With the aim of reducing the noise level, the serration amplitude $(\mathrm{A} / \mathrm{C})$, followed by the serration wavelength $(\lambda / \mathrm{C})$ is the most powerful parameter.

In terms of aerodynamics, leading edge serrations have been shown to delay stall and therefore enable higher maximum stall angles ${ }^{1}$. Numerically, a three-dimensional separation process as a function of the serration parameters could be extracted which highly affects the aerodynamic performance of the aerofoil and confirms the stall-delay effect ${ }^{6}$.This is of special interest for possible fan application as eventually leading edge serrations are intended to be implemented in rotating systems such as counter-rotating rotors, compressors or turbomachines. In the rotating frame, the inflow conditions for the fan blades may vary due to altering operation conditions at varying speeds and flow rates, leading to non-congruent inflow or even to operation conditions near stall ${ }^{7}$. Recently, only little research in this direction has been carried out. Krömer et al. analysed the effect of leading edge serrations on a forward-skewed axial fan with NACA 4510 blades and found only little noise reduction of $1 \mathrm{~dB} \leq \Delta \mathrm{OASPL} \leq 1.8 \mathrm{~dB}$ in maximum ${ }^{8}$. The aerodynamic performance is not reported to be affected by large margins. Further analysis with a rotor featuring flatplate blades, however, showed significantly increased potential for efficiently reducing noise as well as higher aerodynamic efficiencies for serrated blades ${ }^{9}$. Corsini et al. carried out a numerical study on the influence of leading edge serrations or leading edge bumps in the blade tip region, which focused on the aerodynamic stall-resistance improvement ${ }^{10}$. Counter-rotating vortices were observed, which are suspected to enhance the separation control, leading to attached flows, where the baseline blades show separation but suffering a loss in pressure rise of up to $3 \%$. 

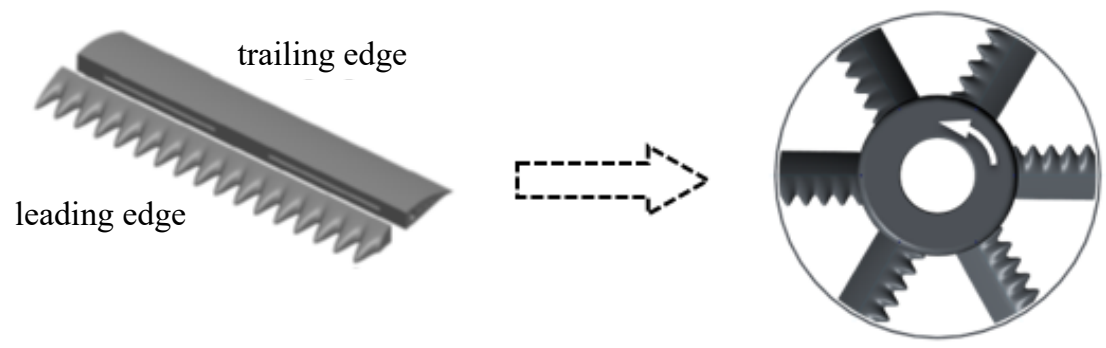

Fig.1, Single aerofoil with leading edge treatment and transfer to rotating frame.

Up to now, no combined test rig is available which allows for simultaneous measurement of aerodynamic and aeroacoustic performance while generating near isotropic turbulence and benefitting from results of already rigidly analysed aerofoils in order to draw direct conclusions on the transfer between the rigid and rotating system. This academic void is approached in the present study. A test rig according to ISO 5136 (Section II) was adopted that allows for simultaneous measurement of aerodynamic and aeroacoustic performance of ducted fans. Using the single aerofoil approach, the already extensively analysed NACA65(12)-10 aerofoil design is chosen, scaled and employed as the fan blades. For the rotor design itself, special care was directed towards an interchangeability of the blades. Different incoming turbulence intensities are generated via coarse biplane square grids (Section III) and quantified via hot wire measurements, covering the full profile of the duct. Spectral analyses of the turbulent signals and comparison to the isotropic turbulence models by Liepmann and Von Kármán result in conclusions on the isotropy of the generated inflow conditions. Eventually, data on the aeroacoustic and aerodynamic fan characteristics with different sets of blades (straight leading edge vs. serrated leading edges) was analysed (Section IV).

\section{Experimental Setup}

\section{A. Test Rig According to ISO 5136}

A test rig according to ISO 5136 - Determination of sound power radiated into a duct by fans and other air-moving devices - In-duct method (ISO 5136:2003) was adopted, where the fan is mounted in a duct of $0.4 \mathrm{~m}$ in diameter and which allows for a simultaneous characterisation of the fan in terms of aeroacoustics and aerodynamics ${ }^{11}$. The standardised bellmouth accounts for smooth inflow conditions, followed by a muffler to dampen the suction side noise (Fig. 2). Subsequently, the determination of the free stream velocity, leading to the volume flow rate, takes place via a pitot tube or an eight-path ultrasonic volume flow analyser, respectively. At a distance of $0.8 \mathrm{~m}$ upstream of the mounted fan, six pressure-tabbing points are located, leading to the physically averaged suction-side pressure. The discharge pressure, however is obtained after the spin has been converted into pressure energy by a star-type flow straightener according to ISO $5801^{12}$. Downstream of the fan a semi-anechoic ending is implemented, preventing back-reflections due to impedance differences at the duct ending. Finally, an automatically driven throttling cone allows for changing the point of operation. In total, the length of the setup sums up to 12 metres. Deviating from the ISO 5136 standard, coarse grids (turbulence grids) needed to be implemented as sources for the broadband leading edge noise of the fan, which is of essential interest in the current study. This took place $0.3 \mathrm{~m}$ upstream of the fan, where grids of specific parameters are implemented as will be discussed in more detail in Section Turbulence. The power unit consists of a high-performance PWM driven (pulse width modulated) e-motor that is commonly used in the automotive industry as it guarantees minimum self-noise as well as small installation dimension and low weight. The rotational speed of the rotor was obtained by use of an acceleration sensor on the fan spindle, representing a minimal-invasive high-resolution method at a frequency resolution of $\Delta \mathrm{f}=0.25 \mathrm{~Hz}$ while, in addition, providing information on the vibrations of the system. In order to cover the acoustic characteristics on the suction and discharge side of the fan, the rig was equipped with two microphone arrays, consisting of four $1 / 4$-inch condenser microphones each, where three of the latter are distributed equidistantly in the circumferential direction and the fourth one exhibits an axial offset of $0.1 \mathrm{~m}$ (Fig. 2). The microphones were used flush-mounted, where a side vented pressure field design allowed for correct equalisation of atmospheric pressure. Additionally, a 1/2-inch Microtech prepolarised condenser microphone was used in a B\&K UA0463 turbulence screen and was mounted in agreement with the ISO 5136 on the discharge side of the fan to gather additional aeroacoustic information. The turbulence screen features high degree of turbulence noise suppression and is especially constructed for measurements of airborne noise in air ducts. Finally, two pressure tabs of $\mathrm{D}=0.9 \mathrm{~mm}$ in diameter, flush-mounted in the rotational axis of the fan at a circumferential distance of one blade passage, were implemented to gain deeper insights in tip-leakage effects and the associated 
influence of leading edge serrations. For all aeroacoustic measurements a sampling rate of $44.1 \mathrm{kHz}$ and a blocksize of 32768 were employed to analyse the spectral data of up to $17 \mathrm{kHz}$ at a frequency resolution of $\Delta \mathrm{f}=1.3 \mathrm{~Hz}$. Applying Hanning windows with an overlap of $66 \%$, the blocks were averaged for 300 times, yielding a total measurement duration of 74 seconds.

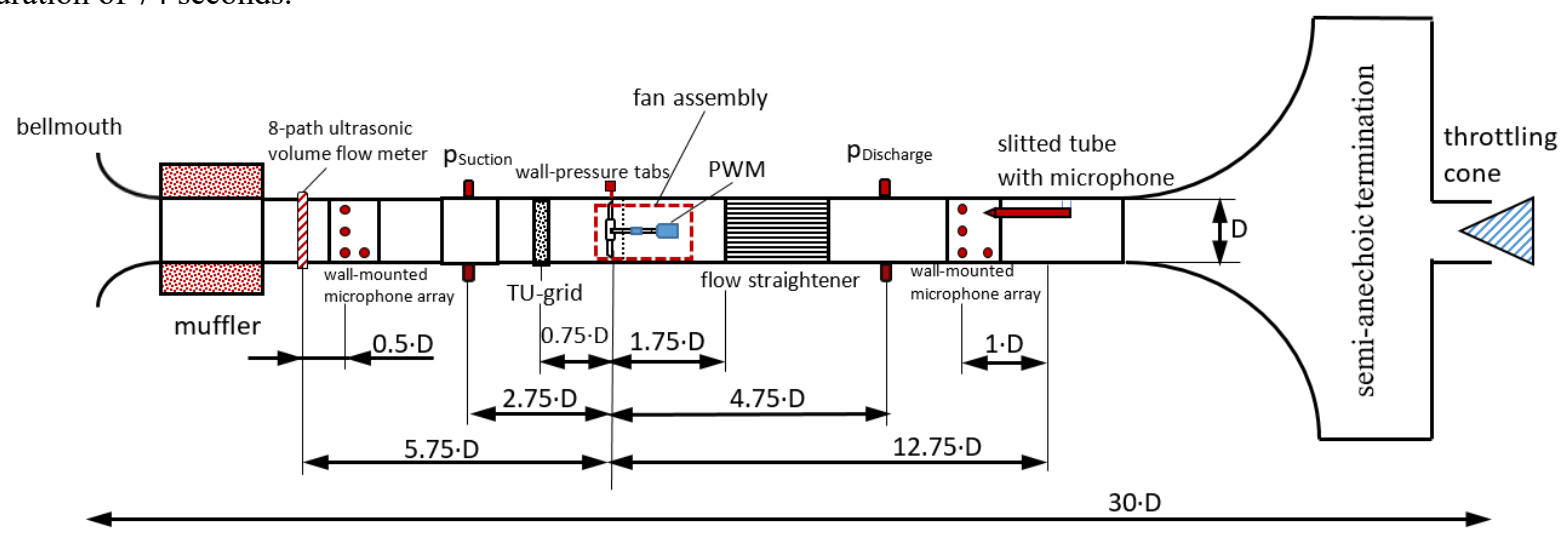

Fig.2, Adopted Test rig according to ISO 5136 and ISO 5801.

\section{B. Rotor Design}

Recently, the NACA(65)12-10 aerofoil was the object of interest in a number of extensive studies on the noise reduction capabilities of serrated leading edges but limited to rigidly mounted settings ${ }^{1-4}$. With the purpose of analysing the transfer process of these passive noise reduction devices to the rotating setting, the same aerofoil type was used for the design of the test rotor. The aim of the research project is to successively increase the complexity of the rotor blades step-by-step to enable a systematic analysis of the serration effects. Straight blades were chosen and scaled according to the required maximum chord length and implemented in a rotating setup. Blade parameters such as the blade sweep, shroud and dihedral are to be analysed in subsequent settings. The design of the rotor took place according to the isolated aerofoil approach, where low solidity blading with large circumferential blade spacing is required to neglect interaction of the blades. ${ }^{13 ; 14}$ The solidity is defined as the quotient of chord $(\mathrm{C}=0.075 \mathrm{~m})$ and pitch. An invisible rotor or a negligible blade interaction, respectively, can be assumed at low solidities $\mathrm{C} / \mathrm{t}<0.7$ (Eq. 1). With a number of six blades, the solidity turns out to be $\sigma=0.36$ for the blade tip and $\sigma=0.72$ for the hub region. Blades with a constant stagger angle corresponding to a blade-congruent inflow at mid-span were chosen as a first approach. Eventually, the stagger angle can be determined as the sum of flow angle and angle of attack, which itself was chosen based on the maximum lift-to-drag ratio of the experimentally and numerically analysed rigid aerofoils 6 ; 1. The hub was designed to be $0.2 \mathrm{~m}$ in diameter, resulting in fan blades of $0.1 \mathrm{~m}$ in span. The most important feature of the fan design is the interchangeability of the blades, leading to cost-effective possibilities of analysing blades of various geometries.

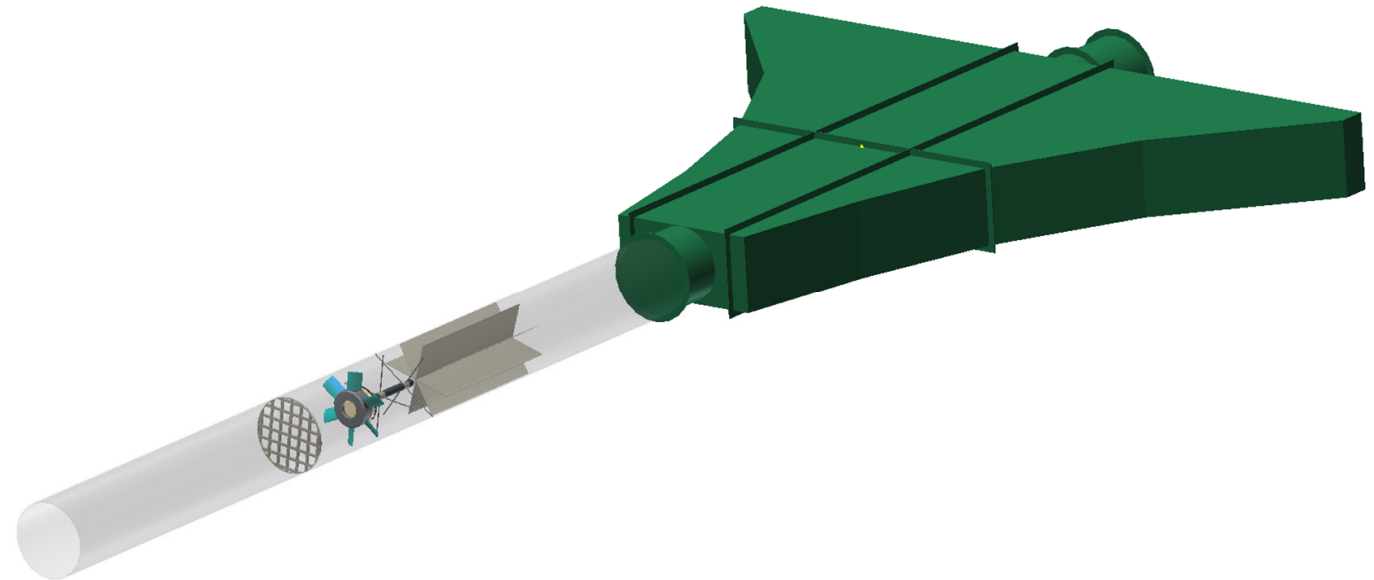

Fig. 3, Test assembly according to ISO 5136 showing the upstream turbulence grid, the rotor, the struts and the startype flow straightener as well as the semi-anechoic termination of the duct. 


$$
\sigma=\frac{C}{t}
$$

\section{Leading Edge Serrations}

As already described in Section Rotor Design, interchangeable rotor blades with leading edge serration of various parameters were tested in terms of the aeroacoustics and aerodynamics. According to the extensive preliminary studies of rigidly mounted serrations, the parameters and dimensions of the serrations were adopted and scaled to the current setup, where the aerofoil chord length was the definitive parameter $6 ; 2 ; 15 ; 16$. Figure 4 shows the scales of importance for the serrations, where the peak-to-peak value is defined as amplitude and the distance between two adjacent serration roots as the wavelength. The maximum serration amplitude was limited to one-third of the aerofoil chord length. The absolute values of the tested cases are listed in Table 1. It is important to note, that the serrations are cut into the aerofoil main body, which keep the maximum chord length $(\mathrm{C}=75 \mathrm{~mm})$ constant. This leads to an amplitudedependent reduction in the aerofoil surface, affecting the aerodynamic performance. On the other hand, keeping the aerofoil surface constant would lead to amplitude-dependent rotor solidity, possibly leading to hardly controllable influences of blade interaction.

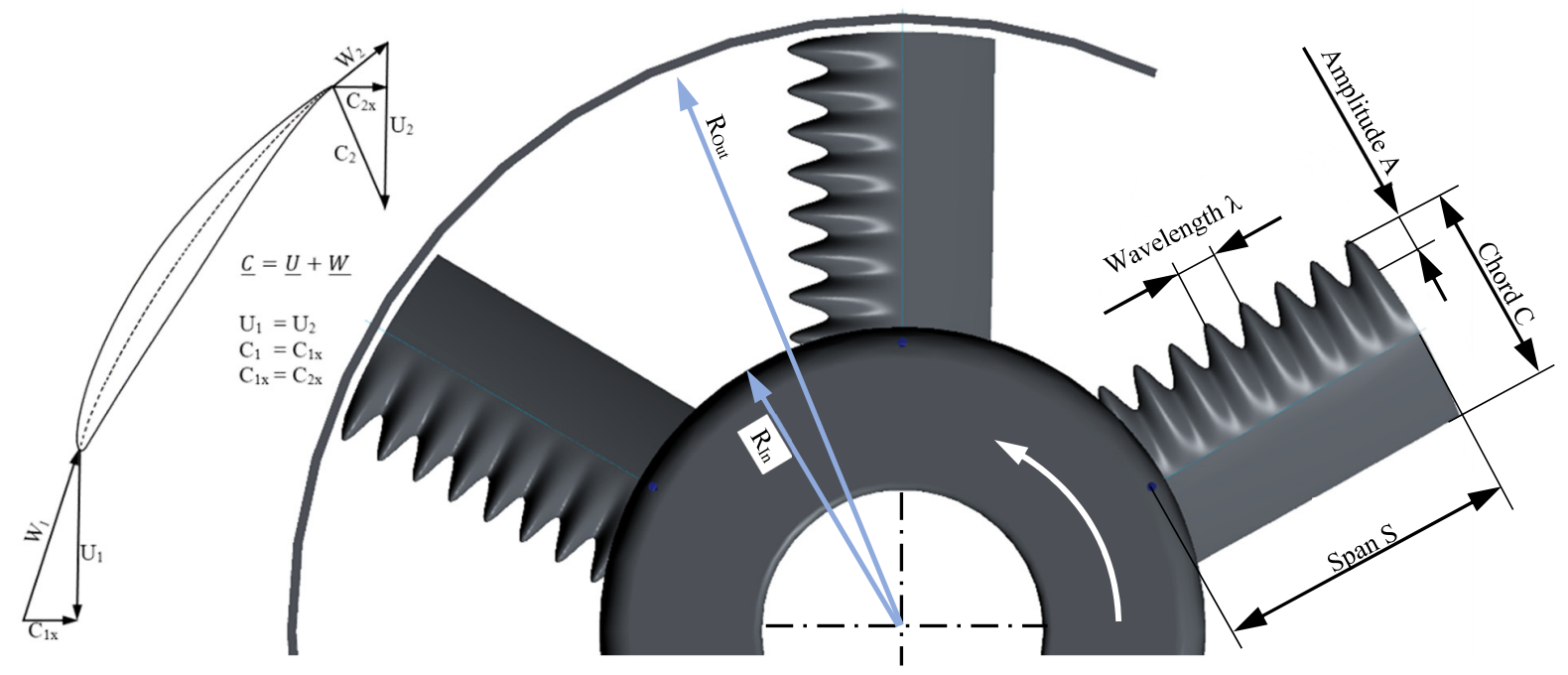

Fig. 4, Left: Velocity triangle of NACA65(12)-10 aerofoil to determine the stagger angle at blade-congruent inflow conditions. Right: Serrated rotor blade including measures of importance. 
Table 1, Left: Tested serration parameters. Right: Classification of the five defined serrated rotors. Variation of serration amplitude and wavelength, starting at an intermediate design of A14 $\lambda 13$.

\begin{tabular}{|c|c|c|c|}
\hline Type & $\begin{array}{c}\text { Amplitude } \\
\qquad \begin{array}{c}\mathbf{A} \\
{[\mathrm{mm}]}\end{array}\end{array}$ & $\begin{array}{c}\text { Wavelength } \\
\boldsymbol{\lambda} \\
{[\mathrm{mm}]}\end{array}$ & $\begin{array}{c}\text { Max. Chord } \\
\text { C } \\
{[\mathrm{mm}]}\end{array}$ \\
\hline BSLN & -- & -- & 75 \\
\hline A $6 \lambda 13$ & 6 & 13 & 75 \\
\hline $\mathrm{A} 14 \lambda 13$ & 14 & 13 & 75 \\
\hline A $22 \lambda 13$ & 22 & 13 & 75 \\
\hline A $14 \lambda 4$ & 14 & 4 & 75 \\
\hline $\mathrm{A} 14 \lambda 22$ & 14 & 22 & 75 \\
\hline
\end{tabular}

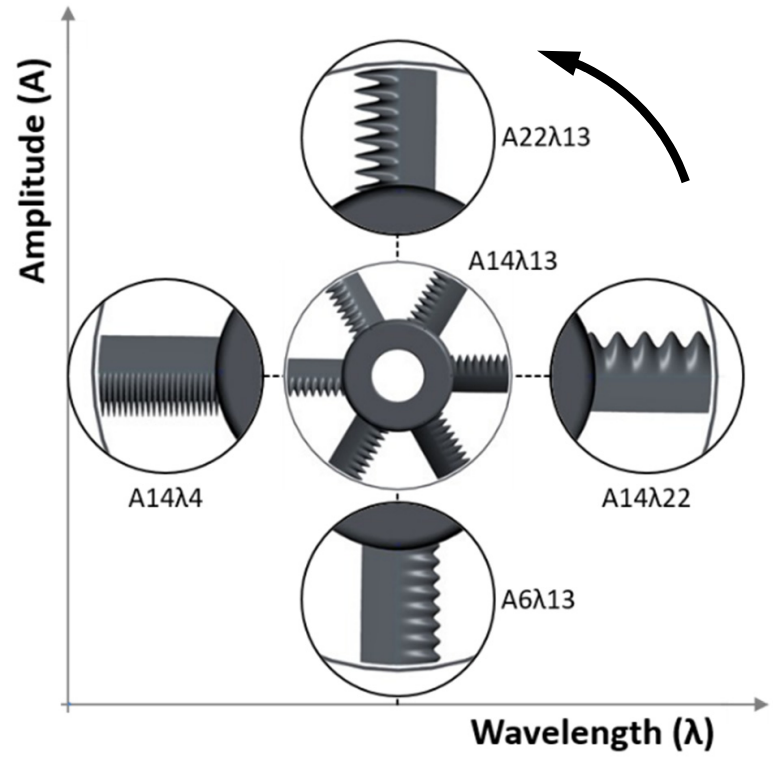

\section{Incoming Turbulence}

The presented study focuses on turbulence-generated aerofoil gust interaction noise, where the leading edge noise of the rotor blades is expected to represent the dominant noise source ${ }^{17-19}$. Hence, high level of turbulence is required. Recent studies and noise prediction models usually refer to turbulence of isotropic or near-isotropic character. To enable a comparison, the same requirement also applies for the current study. According to Laws and Livesey, a constant ratio of mesh size and bar diameter of $\mathrm{H} / \mathrm{d}=5$ are advantageous to generate elevated level of turbulence of high isotropic character at a sufficient distance from the grid ${ }^{20}$. Table 2 (left) shows the grids used in the presented study, including the relevant design parameters. For obtaining data on the local distribution of the free stream velocity and the grid-generated turbulence in the duct, 1-D hot wire measurements were conducted. The setup is reported in more detail in previous publications ${ }^{21}$. Figure 5 (left) exemplarily shows results of the velocity profile in the duct with the features of the classical turbulent velocity profile in form of high gradients close to the wall. With grid, the profile appears to be of more uniform character than without, where the grid might act, apart from generating turbulence, as flow straightener for stabilising the outer regions of the boundary layer. Moving the focus towards the turbulence intensity, a similar pattern as for the velocity profiles can be observed (Fig. 5 - right). For the grid $\mathrm{G}_{03}$, turbulence intensities of up to $10 \%$ are achieved in the centre, showing a uniform distribution. Towards the outer regions, a significant increase of the turbulence intensity is visible which can be clearly assigned to the decreasing denominator in form of the mean velocity due to the no-slip condition at the wall. In order to obtain representative values for each grid, the gathered data was averaged over a radius of $0.15 \mathrm{~m}$ to avoid influences by the wall boundary layer (Table 2 , right). In summary, the grid-generated incoming turbulence for the rotor blades to be analysed is in a range of $3.7 \%$ $\left(\mathrm{G}_{05}\right) \leq \mathrm{Tu} \leq 12.1 \%\left(\mathrm{G}_{01}\right)$.

Equation 2 stipulates an isotropic turbulence intensity where the fluctuations of the velocity are constant in all spatial directions (constant longitudinal to transversal velocity ratio). This is of high importance because the turbulent structures are impinging in circumferential direction on the fan blades rather than in the main flow direction. At given isotropy, the measured velocity fluctuations in mean flow direction can be equated with the fluctuations in circumferential direction and provide a scale of the turbulent inflow conditions at the blade leading edges.

$$
T u_{i s o}=\frac{\sqrt{u^{\prime 2}}}{\bar{U}}
$$


Table 2, Left: Grid nomenclature and parameters of tested grids with constant bar-to-mesh ratio H/d $=5$. Right: Mean values of velocity, turbulence intensity and standard deviation $\sigma$ of the tested turbulence grids, averaged over $\mathrm{R}=0.15 \mathrm{~m}$. Data taken from ${ }^{21}$.

\begin{tabular}{c|ccccccc} 
Type & Unit & $\mathrm{G}_{00}$ & $\mathrm{G}_{01}$ & $\mathrm{G}_{02}$ & $\mathrm{G}_{03}$ & $\mathrm{G}_{04}$ & $\mathrm{G}_{05}$ \\
\hline \hline $\mathbf{d}_{\text {Bar }}$ & {$[\mathrm{mm}]$} & -- & 20 & 16 & 12 & 8 & 4 \\
HMesh $_{\text {Mes }}$ & {$[\mathrm{mm}]$} & -- & 100 & 80 & 60 & 40 & 20 \\
$\mathbf{H} / \mathbf{d}$ & {$[--]$} & -- & 5 & 5 & 5 & 5 & 5
\end{tabular}

\begin{tabular}{c|ccc} 
Type & $\begin{array}{c}\mathbf{U}_{\text {Mean }} \\
{\left[\mathrm{m} \cdot \mathrm{s}^{-1}\right]}\end{array}$ & $\begin{array}{c}\text { Tu Mean } \\
{[--]}\end{array}$ & $\begin{array}{c}\boldsymbol{\sigma} \text { Mean } \\
{\left[\mathrm{m} \cdot \mathrm{s}^{-1}\right]}\end{array}$ \\
\hline $\mathrm{G}_{01}$ & 11.27 & 0.121 & 1.36 \\
$\mathrm{G}_{02}$ & 11.97 & 0.097 & 1.15 \\
$\mathrm{G}_{03}$ & 11.77 & 0.078 & 0.90 \\
$\mathrm{G}_{04}$ & 11.58 & 0.059 & 0.67 \\
$\mathrm{G}_{05}$ & 12.19 & 0.037 & 0.43 \\
$\mathrm{G}_{00}$ & 13.32 & 0.026 & 0.35
\end{tabular}
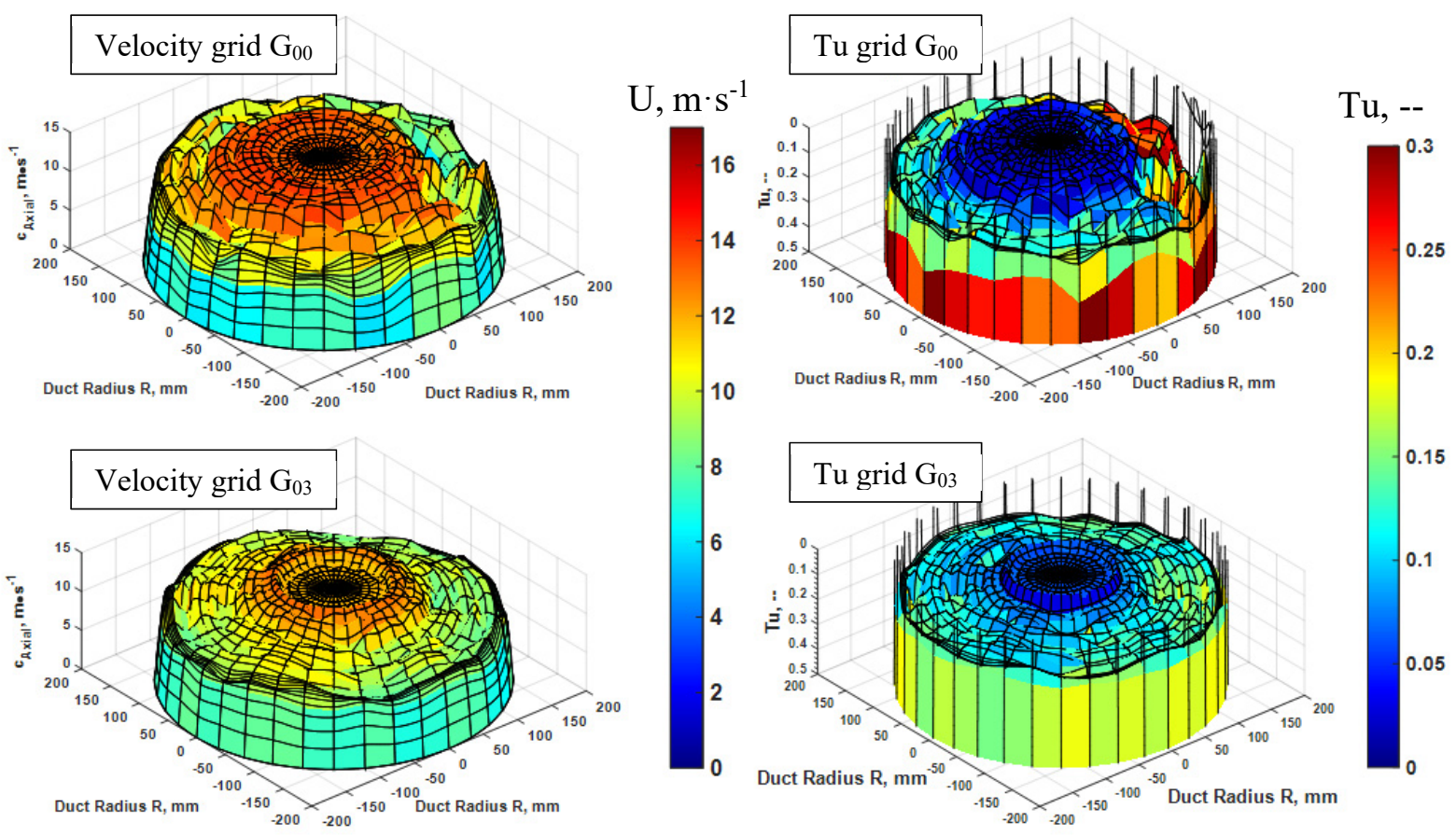

Fig. 5, Local velocity profiles (left) and turbulence profiles (right) in the duct, equidistant increment of $10 \mathrm{deg}$, w/o grid $\left(\mathrm{G}_{00}\right.$, top) vs. $\mathrm{G}_{03}$ (bottom).

Therefore, spectral analysis of the 1-D hot wire signals was conducted and compared to the turbulent energy spectra of Liepmann for longitudinal isotropic turbulence. Figure 6 shows the power spectral density of the turbulent energy, scaled with the mean flow velocity and plotted over the non-dimensional Strouhal number. Data sets of grid $\mathrm{G}_{00}$ (without grid) and $\mathrm{G}_{03}$ are analysed at radial positions of $0.15 \leq \mathrm{R}_{\text {Duct }} \leq 0.198$, starting at mid-span of the fan blades $(\mathrm{R}=0.15 \mathrm{~m})$ towards the wall region of the duct $(\mathrm{R}=0.198 \mathrm{~m})$. The results demonstrate that the turbulence model according to Eqs. 3 - 4 agrees well with the measurements although larger deviations occur close to the wall, especially at high frequencies. A similar trend is observed when increasing the grid dimensions $\left(\mathrm{G}_{00} \rightarrow \mathrm{G}_{03}\right)$ where highfrequency deviations become more prominent. The turbulent cascade theory describes the turbulent energy to scale with $\mathrm{f}^{-5 / 3}$ in the inertial range and $\mathrm{f}^{-7}$ in the dissipation range what can be confirmed for the former range while a diffuse transition to the latter region is observed. Generally, the turbulence intensity is shown to be of near-isotropic nature even for the coarse grids with large mesh widths. 


$$
\begin{gathered}
\Phi_{u u}^{L}(\omega)=\frac{\overline{u^{\prime 2}} \Lambda_{u u}}{\pi U_{0}} \cdot \frac{1}{1+K_{x}^{2} \Lambda_{u u}{ }^{2}} \\
G_{\text {Kolm. }}=\exp \left((-9 / 4) \cdot\left(K_{x} / K_{\eta}\right)^{2}\right)
\end{gathered}
$$
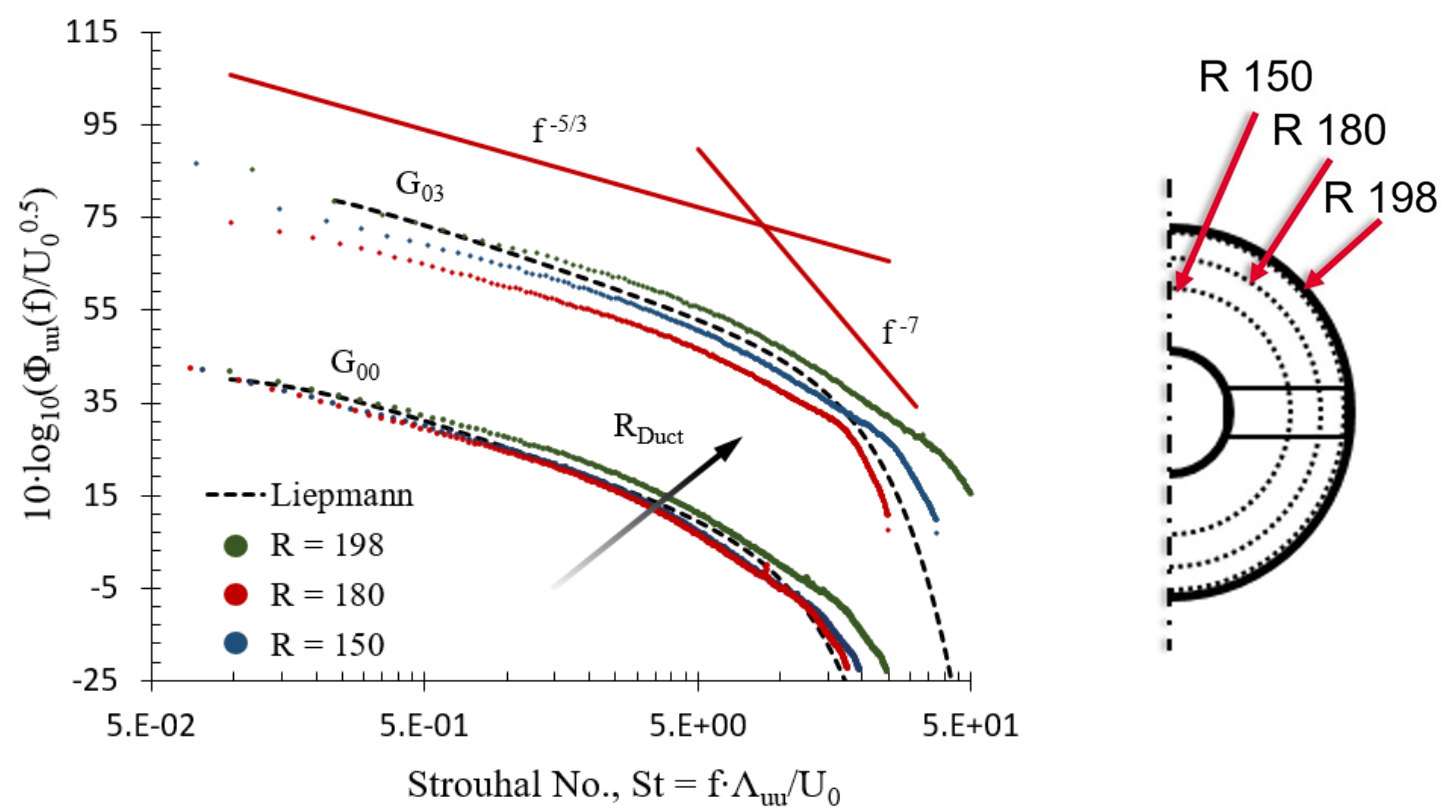

Fig. 6, Power spectral density acc. to Eqs. 3 - 4 of grid-dependent turbulent energy vs. Strouhal number at duct radius $\mathrm{R}=198 \mathrm{~mm}$ (blade tip), $180 \mathrm{~mm}$ and $150 \mathrm{~mm}$ (blade mid-span). Data sets of $\mathrm{G}_{00}$ shifted by $-30 \mathrm{~dB}$.

\section{Results}

\section{A. Aerodynamics}

As mentioned previously, a test rig enabling the simultaneous measurement of aerodynamic and acoustic parameters was defined in order to allow a rating of the efficiency of noise reduction by leading edge serrations, taking into account the influences on the aerodynamic performance. A valid comparison of various measured serration designs as well as the baseline is given by defining the non-dimensional pressure value (Eq. 6) and the flow value (Eq. 7). Differences in ambient conditions are compensated for by normalising the static pressure rise by the air density. As the serrations are cut into the aerofoil main body the resulting surface area decreases as a function of the serration amplitude what consequently leads to a decrease in lift and thus static pressure rise. However, in the context of normalising the fan performance curves, the rotor diameter, element of the rotational velocity, is set to a representative diameter, reflecting the real surface area of the specific rotor. The aerodynamic efficiency is defined by the quotient of aerodynamic and electric power (Eq. 5), however, without taking into account the efficiency of the e-motor itself. Figure 7 (left) shows the fan characteristic curves for six rotors of different leading edge treatment including the reference baseline case with a straight leading edge. The rotor blades exhibit a constant stagger angle, representing blade congruent inflow conditions at mid-span and free vortex design. At the design flow rate of $\varphi=0.19$ no significant differences between the tested cases are visible. However, in the stall regime at low flow rates serrations of relatively low wavelength-to-amplitude ratio $\lambda / \mathrm{A} \leq 0.6$ show a clear tendency of a lower static pressure rise. This pattern was observed to be independent of the turbulence grids used and is expected to be caused by the occurrence of the crossflows at the serration roots at high stagger angles or low flow values, respectively. The crossflow turns out to be of increased significance, either when a higher number of roots is present, as it is the case at low serration wavelengths or at large serration amplitudes by which the crossflow effect can be stabilised. The increased interaction between fan pressure side and suction side affects the capability of maintaining high pressure differences under extreme operation conditions. 
In terms of efficiency (Fig. 7, right), at moderate wavelength-to-amplitude ratios, no big differences to the baseline case were observed even though the maximum wavelengths lead to slightly higher efficiencies than for the baseline rotor. This fits to numerical and experimental results of rigid mounted serrated aerofoils where large serration wavelengths turned out to be of significant aerodynamic importance for obtaining maximum lift coefficients.

$$
\begin{gathered}
\eta_{\text {System }}=\frac{\dot{Q} \cdot \Delta p}{P_{\text {Elec }}} \\
\Psi=\frac{\Delta p / \rho}{U_{\text {rot. }}^{2} / 2} \\
\Phi=\frac{\dot{Q}}{U_{\text {rot }} A}
\end{gathered}
$$
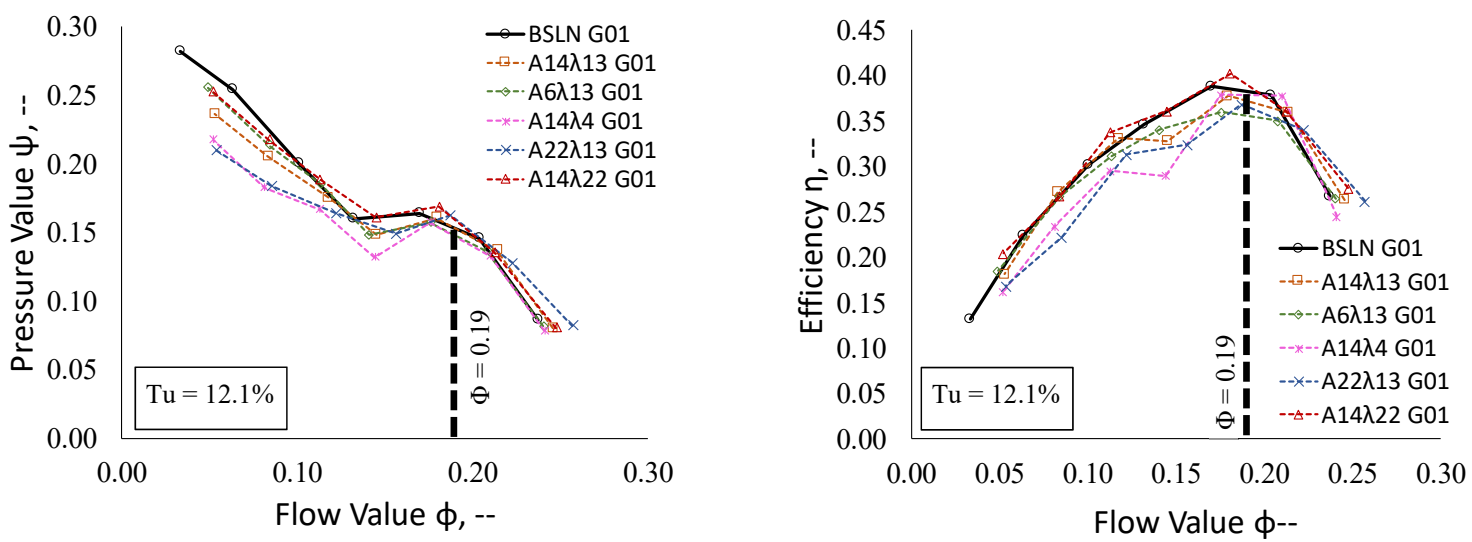

Fig.7, Fan characteristic curves (left) with turbulence grid $\mathrm{G}_{01}$ and $\mathrm{Tu}=12.1 \%$ as well as system efficiency (right).

\section{B. Aeroacoustics}

All designed rotors were tested at various operating conditions, covering the full fan characteristic curves. In terms of turbulence, the previously described turbulence grids were tested. Figure 8 shows the overall sound pressure level reduction $(\triangle \mathrm{OASPL})$ compared to the baseline case in a frequency band of $10 \mathrm{~Hz} \leq \mathrm{f} \leq 10 \mathrm{kHz}$. Three specific operating points at a high flow value, at the rotor design point and in the stall regime at low flow values are shown exemplarily in order to demonstrate the distinctive sensitivity of serrations towards the point of operation. At the design point $(\varphi=0.19)$ a continuous increase of the noise reduction capability with increasing serration wavelength was observed. This result was rather unexpected as for rigidly mounted aerofoils small wavelengths lead to maximum noise reduction even though it has been stated by Chaitanya et al. ${ }^{15}$ that the wavelength needs to correspond to the specific integral length scale of the approaching turbulent structures in order to excite the shoulders of the serrations incoherently. If it can be further validated that relatively large wavelengths lead to a benefit in noise reduction, one of the classic dilemmas in aeroacoustic design by name of opposing trends in terms of aerodynamics and acoustics can be solved as large wavelengths are beneficial for both categories. Increasing the serration amplitude at constant wavelength, however, does lead to an increase of the noise reduction and matches the results of previously conducted studies of rigid aerofoils. With regard to the whole possible range of operation, serrations of low $\lambda / \mathrm{A}-$ ratio seem to be the most stable choice to achieve significant noise reduction over a wide range of operation. At high flow values the noise reduction capability diminishes rapidly under high turbulent inflow conditions. For Grid $\mathrm{G}_{01}$ the serrations of high wavelength to amplitude ratio $1.6 \leq \lambda / \mathrm{A} \leq 2.2$ even seem to show an increase of the radiated noise when compared to the reference rotor. This range is even broadened at lower turbulence intensities (grid $\mathrm{G}_{04}$ ) to $0.6 \leq \lambda / \mathrm{A}$ $\leq 2.2$. Thus, despite showing the maximum noise reduction capability at the design point, serration of high $\lambda / \mathrm{A}-\mathrm{ratio}$ seem to be highly sensitive towards non-congruent inflow conditions. 
Going deeper into finding the reasons for the extreme noise reduction for the A14 222 case of $\triangle \mathrm{OASPL}=7.14 \mathrm{~dB}$ or $\triangle \mathrm{OASPL}=13 \mathrm{~dB}$, respectively, reveals the significance of a combined analysis of aerodynamics and aeroacoustics. As has been reported previously for studies on single aerofoils, intermediate to large wavelengths are beneficial in keeping the boundary layer attached to the aerofoil when increasing the angle of attack ${ }^{6}$. Thus, the stall region can be significantly delayed and takes place more smoothly compared to the baseline case. The design point of the rotor is close to the instability region of the fan where stall occurs and, as a consequence, causes both, a stagnating static pressure rise but also significant noise radiation due to separating large-scale structures, mainly in the low-frequency range. Given the same flow value, at which the baseline case already enters the stall region but the serrated case doesn't, will lead to huge differences in the noise emission as entering the stall region might easily lead to an extra 10 $\mathrm{dB}$ noise increase. Suddenly and in contrast to previously analysed rigidly mounted aerofoils with and without serrations, one has to distinguish acoustic effects which can be either linked to aerodynamic flow phenomena (delayed stall) or to aeroacoustic effects (incoherent excitation, decorrelation effects ${ }^{15 ; 22}$ ). Even though it has been shown by Hansen et al. and others ${ }^{23 ; 24 ; 22}$ that leading edge serrations are also able to reduce trailing edge noise, the discussed pattern of delayed stall is still expected to be one of the main reasons for efficiently reducing noise when no grid is employed and, in this case, the leading edge noise is not the dominant source of the rotor.
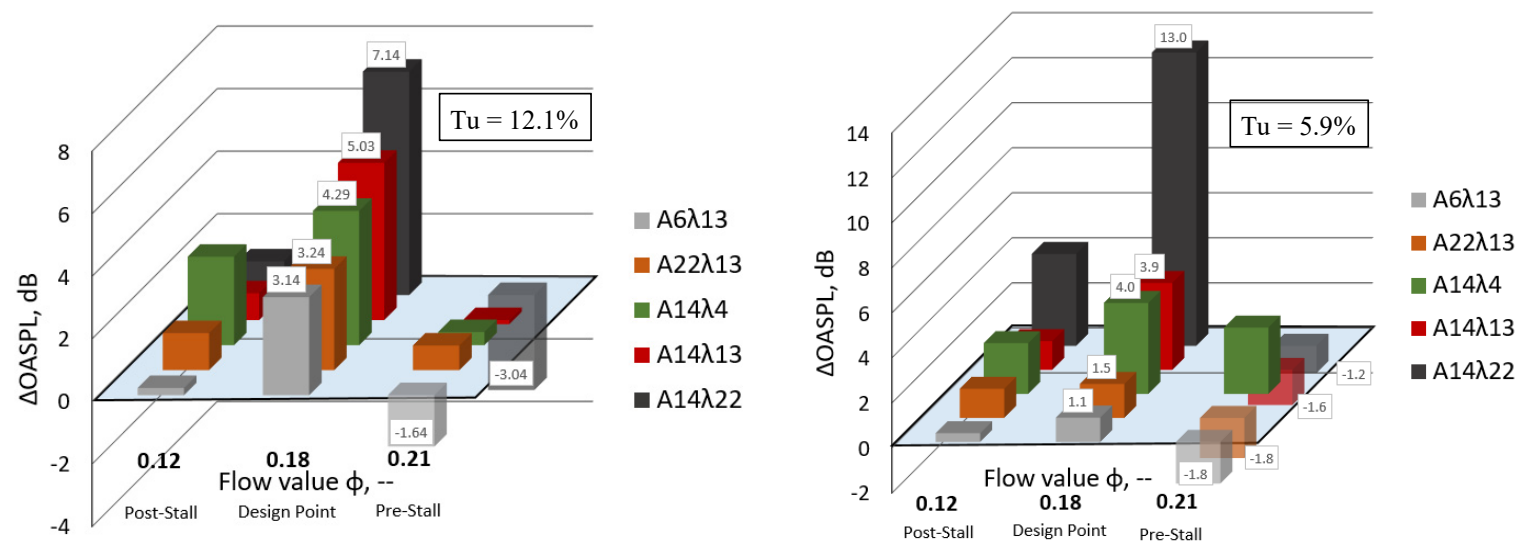

Fig.8, Total noise reduction at high-turbulent inflow conditions (left, Grid $\mathrm{G}_{01}$ ) and at low turbulence (right, Grid $\mathrm{G}_{04}$ ) for three characteristic operation points. Noise reduction on the fan suction side.

Apart from analysing the overall effect of serrated leading edges, spectral insights are of interest when it comes to the identification of noise reduction mechanisms. Figure 9 shows spectral differences of a rotor featuring A14 13 serrations and a corresponding baseline case at four different flow values. Positive differences between the cases tested are coloured red whereas negative effects $\left(\mathrm{SPL}_{\mathrm{BL}}>\mathrm{SPL} \mathrm{Serr}\right)$ are indicated in green. In addition, the overall levels are indicated in the boxes top right. Starting at maximum flow values $\varphi=0.24$ only little noise reduction can be observed though it is of broadband character and visible up to $10 \mathrm{kHz}$. Approaching flow values close to the design point $\varphi=$ 0.17 shows a significant increase in the broadband noise reduction, also affecting tonal components such as the first and second $\mathrm{BPF}$ at 201 and $402 \mathrm{~Hz}$ which are reduced by $\Delta_{\mathrm{BPF} 1}=2 \mathrm{~dB}$ and $\Delta_{\mathrm{BPF} 2}=4 \mathrm{~dB}$, respectively. The total noise reduction turns out to be $\triangle \mathrm{OASPL}=4.9 \mathrm{~dB}$. At $\varphi=0.11$ the serrated case exhibits a noise increase compared to the baseline which can mainly be assigned to the low frequency region $10 \mathrm{~Hz} \leq \mathrm{f} \leq 300 \mathrm{~Hz}$ where large-scale rotating structures such as rotating stall occur at circumferential velocities smaller than the rotor speed. The increase of the noise mainly occurs due to the fact that the baseline rotor already left the instability region at $\varphi=0.11$ while the serrated rotor still suffers stall effects. Operating the fan under extreme conditions at minimum flow values $\varphi=0.04$, the noise reduction eventually increases again, efficiently reducing stall-effects and tip leakage noise at low frequencies. 

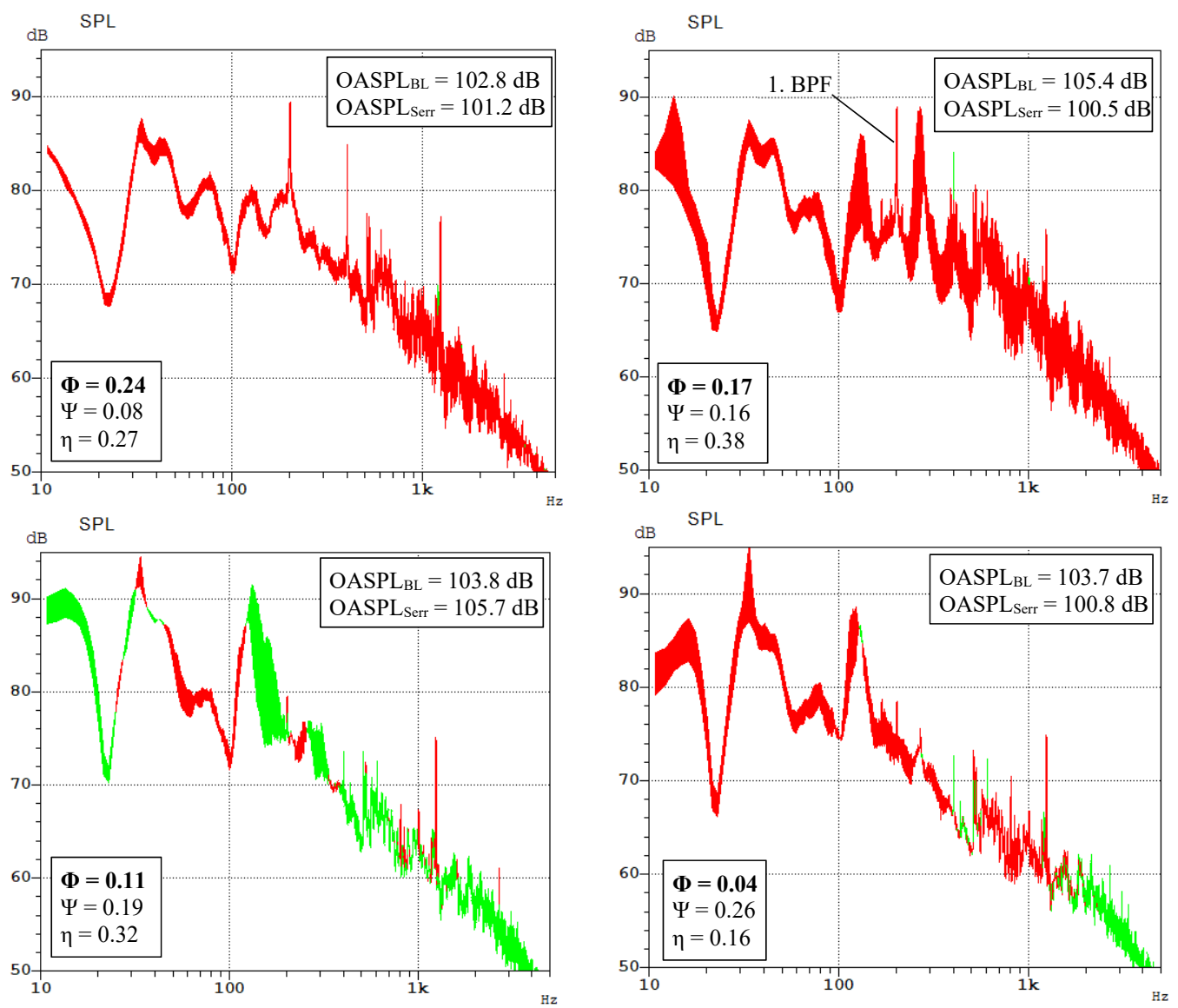

Fig.9, Spectral noise reduction (red) and increase (green) for a serration (Serr) of intermediate dimensions

A14 13 compared to the baseline case (BL). High-turbulent inflow Grid $\mathrm{G}_{01}$.

With the aim of gaining deeper insights into the specific noise reduction effects of serrated blades; a set of five spectral bandpass filters was defined for separately analysing the aeroacoustic impact. In general, all acoustic signals are limited by a lower frequency of $\mathrm{f}_{\min }=10 \mathrm{~Hz}$ to make sure that the first blade harmonic at RPM $=2000 \mathrm{~min}^{-1}$ or $33.33 \mathrm{~Hz}$ is included. The experimental setup consists of a steel duct at given wall-thickness of $4 \mathrm{~mm}$ which can be assumed reverberant, therefore justifying the chosen lower frequency. The upper limit is at $\mathrm{f}_{\max }=10,000 \mathrm{~Hz}$, as this represents the maximum allowed frequency according to ISO 5136. These limiting frequencies are represented by the total bandpass filter (Table 3). Especially at extreme operation points; low-frequency components $\leq 300 \mathrm{~Hz}$ become dominant in the acoustic spectrum due to large scale separation from the rotor blades. The effect of this region on the serration noise reduction capability is expressed by the low-frequency filter. The tonal filter, however, extracts all speed-related tonal components such as blade harmonics and blade passing frequencies in the bandwidth $10 \mathrm{~Hz} \leq \mathrm{f} \leq$ $2 \mathrm{kHz}$ as this is the dominant frequency range for tonal effects. The broadband filter represents the negative of the tonal filter, by taking into account all spectral content except for the tonal effects. Defining the sum of the OASPL for the tonal and the broadband filter yields the total OASPL in the frequency range $10 \mathrm{~Hz} \leq \mathrm{f} \leq 10 \mathrm{kHz}$ (e.g. $92.6 \mathrm{~dB}+$ $91.9 \mathrm{~dB}=95.3 \mathrm{~dB}$, see Fig. 10). Finally, the BPF filter defines the sum level of the first five blade passing frequencies. Due to the relatively coarse frequency resolution of $\Delta \mathrm{f}=1.34 \mathrm{~Hz}$, the bandwidth of the filters yields to be $9.4 \mathrm{~Hz}$, covering \pm 3 samples around the frequency line of interest. Differences between the broadband and the total filter indicate significant influences of the tonal components (up to $\mathrm{f}=2 \mathrm{kHz}$ ). The estimated error which occurs due to the missing frequency lines for the broadband filter is $\triangle \mathrm{OASPL}=0.3-1.3 \mathrm{~dB}$ (compared to the total level at $10 \mathrm{~Hz} \leq \mathrm{f} \leq$ $10 \mathrm{kHz}$ ) but needs not to be taken into account as the relative comparison does not suffer any lack of validity. A filtered signal is exemplarily shown in Fig. 10. 
Table 3, Parameters of the customised filters.

\begin{tabular}{c|cccc} 
Type & $\begin{array}{c}\mathbf{f}_{\text {Min }} \\
{[\mathrm{Hz}]}\end{array}$ & $\begin{array}{c}\mathbf{f}_{\text {Max }} \\
{[\mathrm{Hz}]}\end{array}$ & $\begin{array}{c}\text { increment } \\
{[\mathrm{Hz}]}\end{array}$ & $\begin{array}{c}\text { bandwidth } \\
{[\mathrm{Hz}]}\end{array}$ \\
\hline \hline Total & 10 & 10,000 & 1.34 & 1.34 \\
Low-frequency & 10 & 300 & 1.34 & 1.34 \\
Tonal & 10 & 2000 & 33 & 9.4 \\
Broadband & 10 & 10,000 & 1.34 & 24 \\
BPF & 201 & 1006 & 201 & 9.4
\end{tabular}

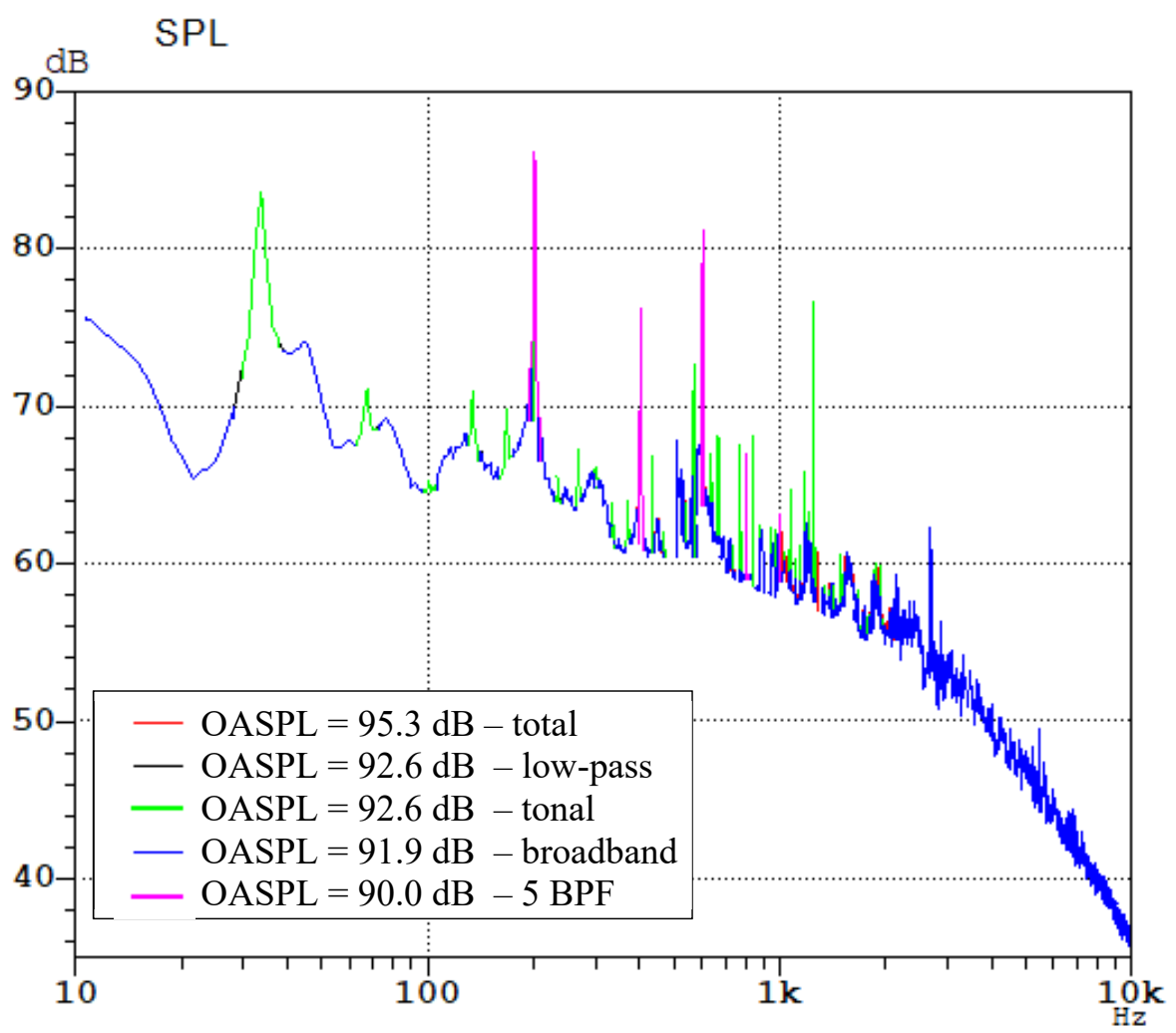

Fig.10, Spectrum of baseline rotor with $\mathrm{Grid}_{00}$ at $\varphi=0.18$, filtered exemplarily. Total filter (red), low pass filter (black), tonal filter (green), broadband filter (blue) and BPF filter (pink).

Figures 11 - 12 shows the breakdown individual share of noise reduction for a serration design of intermediate

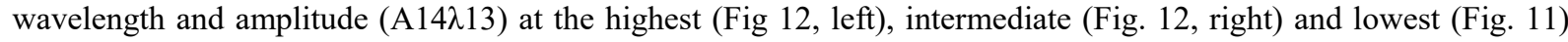
incoming turbulence intensity. If no turbulence grid is applied (Fig. 11, $\mathrm{G}_{00}$ ) a noise reduction for all tested flow values can be observed. However, the noise reduction tends to increase towards the design point of the fan $(\varphi=0.19)$. One exception are extraordinary small flow values where a very high noise reduction takes place, which is expected to be due to large-scale flow separation at the fan blades. Analysing the fractions in terms of the different applied filters for the no-grid case shows a clear domination of the tonal noise reduction of up to $\Delta \mathrm{SPL}=4.1 \mathrm{~dB}$ at $\varphi=0.17$. In summary, the tonal and the BPF noise reduction show a dependency on the throttling state and increase from high flow values to the design point and decrease when the flow values are further reduced. The impact of the broadband noise reduction as well as the low-frequency portion remains almost constant over a wide range of flow values. 


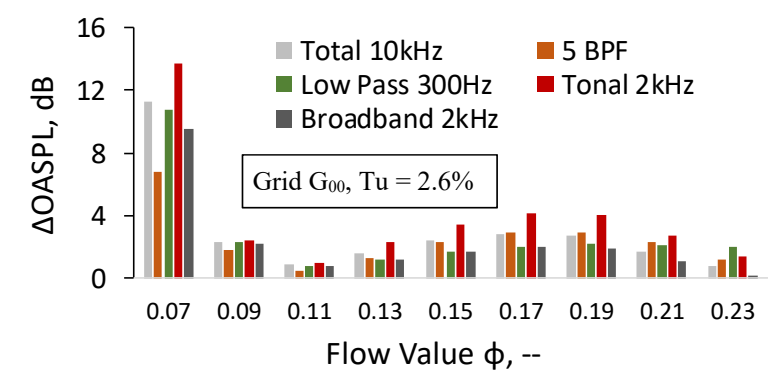

Fig.11,Partial noise reduction by means of different applied filters as a function of flow value $\varphi$. A14 113 case, $\mathrm{G}_{00}$ (no grid).

Moving the focus towards high turbulent inflow conditions (Fig. 12) reveals a significant increase of the broadband noise reduction, which turns out to be a function of the flow value with its maximum at the design point and a decreasing pattern towards higher or lower flow values. The same applies for the low-frequency portion. In general, a more efficient noise reduction is achieved at high turbulent inflow conditions, which serves as indicator for efficient reduction of broadband leading edge noise. The significant low-pass fraction in terms of noise reduction backs the findings described previously when it comes to a delay in stall as a function of the serration design and the point of operation and therefore plays a crucial role in reducing fan noise. However, at high flow values and under high turbulent inflow the serrations turn out to produce higher noise level than the baseline case. This can partly be assigned to a specific pattern of the serrations, already analysed at rigidly mounted serrated aerofoils ${ }^{2}$. At high flow values the angles of attack are negative which leads to a significant increase of rotor blade self noise. Comparing the influence of different turbulence grids shows a tendency of increasing noise reduction with increasing incoming turbulence $\left(\mathrm{G}_{00}\right.$ $\left.\rightarrow \mathrm{G}_{04} \rightarrow \mathrm{G}_{01}\right)$.
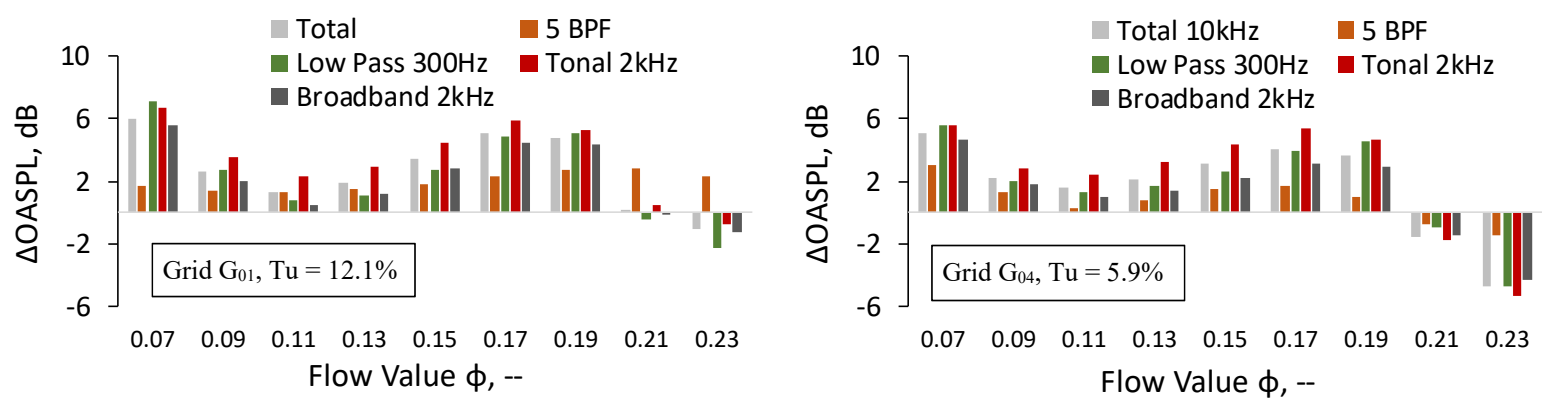

Fig.12,Partial noise reduction by means of different applied filters as a function of flow value $\varphi$. A14 1313 case at high turbulence intensity $\mathrm{G}_{01}$ (left) and intermediate turbulence intensity $\mathrm{G}_{04}$ (right).

\section{Advanced Serration Design Results}

In the context of studying the effect of leading edge serrations on the broadband noise reduction several researchers suggested serrations of modified shape to achieve a further improvement of the noise reduction. However, the suggestions made were based on numerical ${ }^{25}$ and experimental work ${ }^{3 ; 15}$ with rigidly mounted aerofoils undergoing turbulent distortion. In addition, early studies on rotating serrations such as conducted by Corsini et al..$^{10}$ focussed on modifying a limited area close to the blade tip as this is the region where the acoustic sources of maximum strength are expected as well as where the maximum lift is generated. Modifying solely the relevant area in terms of aerodynamics and acoustics brings clear advantages in terms of improved aerodynamic performance while maintaining a maximum noise reduction. Therefore, both approaches were followed in the presented study, where one advanced serration design is to compare with an already efficient serrated reference design. As stated in Eq. 8, a sinusoidal design featuring double-amplitudes was defined by setting the parameters amplitude A, wavelength $\lambda$, span $\mathrm{S}$ and control variable $\mathrm{x}$, where each major peak is followed by a considerably smaller peak at the root location of the

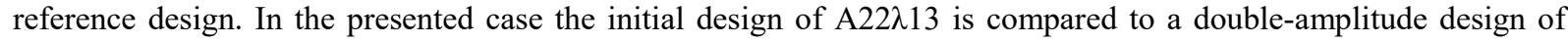
A22A11 $\lambda 6.5$ where $\lambda 6.5$ stands for the distance of two adjacent peaks. The wavelength of two peaks of the same amplitude remains at $\lambda 13$. 

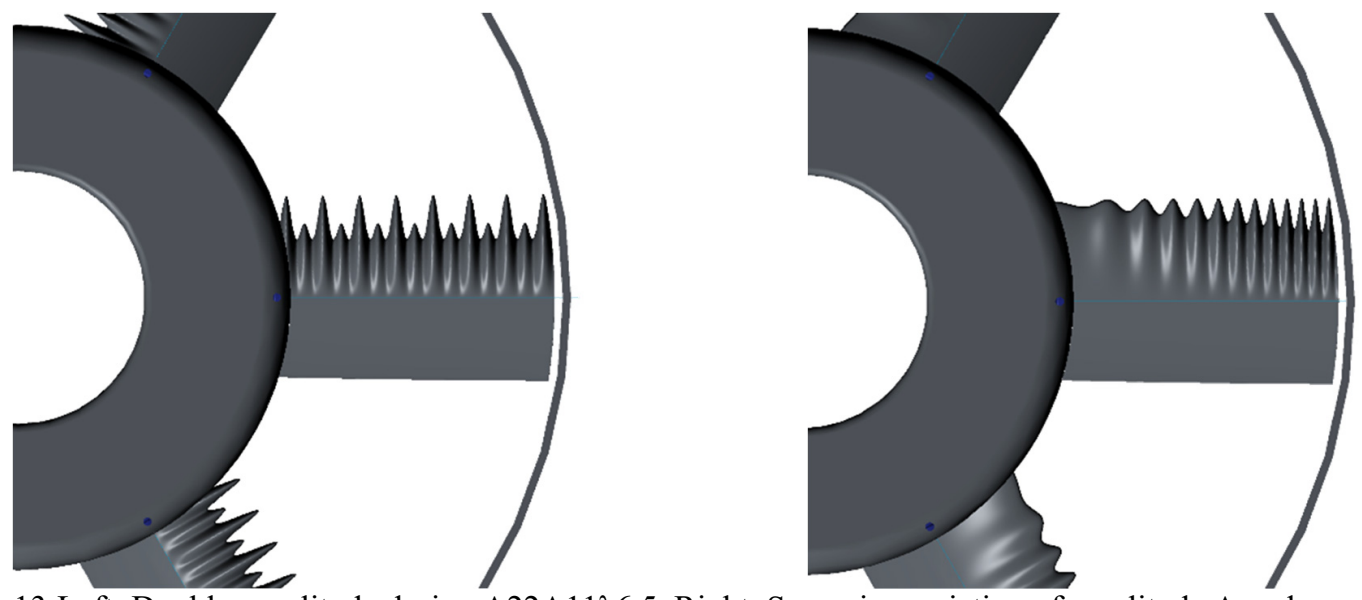

Fig.13,Left: Double-amplitude design A22A11 $\lambda 6.5$. Right: Spanwise variation of amplitude A and wavelength $\lambda$

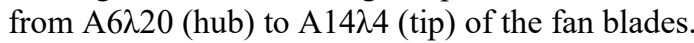

Figure 14 shows the resulting aerodynamic and aeroacoustic performance. Normalising for differences in effective surface area leads to an aerodynamic performance of high similarity although slightly higher pressure values and efficiencies are obtained by the double-amplitude design. In terms of acoustics, the resulting overall levels are comparable to those of the reference serration at the design point. Especially at higher flow rates, however, the doubleamplitude design shows higher levels. In conclusion, the tested double-amplitude design is well suited for an efficient noise reduction but, at least for the tested configuration, it does not beat the initial design of single amplitudes.

$$
y(x)=A_{1} \cdot \sin \left(x \cdot \frac{S}{\lambda}\right)+A_{2} \cdot \sin \left(2 \frac{x \cdot S}{\lambda}\right) \text { where } x \in(0, S)
$$
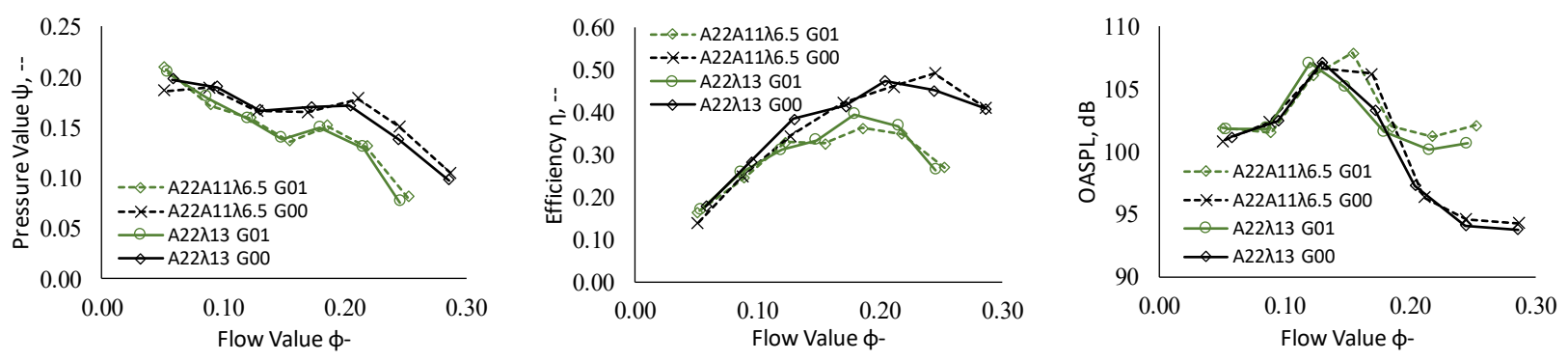

Fig.14,Fan characteristic curves (left), efficiency curves (centre) and aeroacoustic characteristics (right) of double serration design A22A11 $\lambda 6.5$ vs. reference serration $A 22 \lambda 13$ at low $\left(\mathrm{G}_{00}\right)$ and maximum $\left(\mathrm{G}_{01}\right)$ turbulence intensity.

In order to maximise the effective surface area of the blades, a serration design of variable amplitude and wavelength was tested. According to Eq. 9, the initial design at the fan hub is A6 220 where the amplitude increases and the wavelength decreases with the blade span S towards an A14 4 design at the blade tip, which, in addition, represents the reference design for evaluating the aeroacoustic and aerodynamic performance. The factor B controls the slope of amplitude increase and is set to $\mathrm{B}=2$. For the presented case the total surface area is increased by $4 \%$ compared to the serrated reference design A14 $\lambda$. As Fig. 15 shows, the aerodynamic performance seems not to be affected by high degrees, only showing slight improvement at very low flow values, which might be due to a reduction in crossflow effects due to the higher serration wavelengths at the fan hub. However, the efficiency slightly increased but so did the acoustic radiation. Albeit no noteworthy improvement in neither aerodynamics nor aeroacoustics could be observed, the fact that an aeroacoustically disadvantageous serrated design close to the fan hub does not affect the overall performance, indicates the importance of the fan blade tip region for acoustic radiation and optimisation.

$$
y(x)=A \cdot(1-x)+A \cdot(1-x) \cdot \sin \left[(1-x)^{B} \cdot \frac{S}{\lambda \cdot B}\right] \quad \text { where } x \in(0, S)
$$

American Institute of Aeronautics and Astronautics 

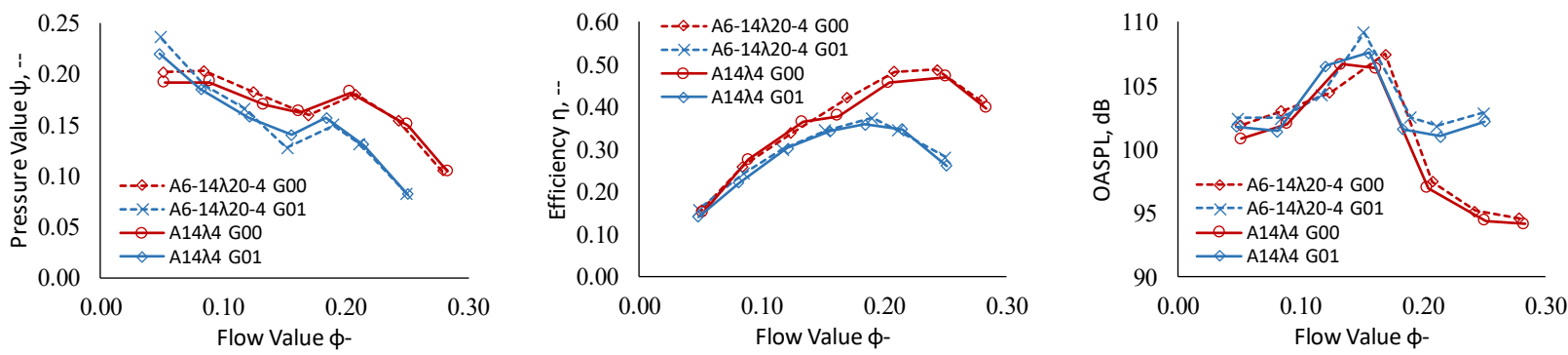

Fig.15,Fan characteristic curves (left), efficiency curves (centre) and aeroacoustic characteristics (right) of

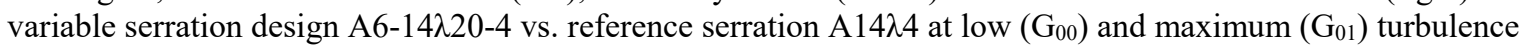
intensity.

\section{Conclusions}

A test rig according to ISO 5136 was adopted and modified with the aim of analysing low-pressure axial fans. A rotor with interchangeable three-dimensional blades according to the NACA65(12)-10 was designed to analyse serrated leading edges and allow a variation of several parameters such as the blade design (sweep, skewness, dihedral ...), the serration design (amplitude, wavelength ...) and the rotational speed. Moreover, the defined test rig allows for an analysis of both, aerodynamic and aeroacoustic performance for the whole fan characteristic diagram. As a first step towards the analysis of rotating serrations, experiments with five sets of serrations as well as one baseline case (straight leading edge) and two sets of more advanced serration designs were conducted at different incoming turbulence intensities, covering the whole fan characteristic curve. The results obtained allow the current paper to reach the following conclusions:

- Aerodynamically, no significant differences between the tested serrations occur at the design point, however, in the stall regime serrations of relatively low wavelength-to-amplitude ratio $\lambda / \mathrm{A} \leq 0.6$ show a clear tendency towards a lower static pressure rise.

- In general, the noise reduction capability turns out to be a function of the operating point of the fan where the most efficient noise reduction takes place at the design point and shows less efficient performance in the instability region where (partial) stall occurs. Moreover, scaling of the noise reduction with serration parameters shows to be dependent on the operation point as well.

- The noise reduction due to serrated leading edges was found to be of both, tonal and broadband character, where predominant aeroacoustic effects are mainly limited to $\mathrm{f} \leq 2 \mathrm{kHz}$, in the stall region even limited to $\mathrm{f}$ $\leq 300 \mathrm{~Hz}$.

- The influence of serration wavelength-to-amplitude ratio $\lambda / A$ seems to play a crucial role in terms of noise reduction capability (max. overall noise reduction $\triangle \mathrm{OASPL}=13 \mathrm{~dB}$ ). In general, large wavelengths and intermediate to large amplitudes lead to the highest noise reduction whereas similar magnitudes of wavelength and amplitude lead to a more stable performance and a continuous noise reduction in the full operational range of the fan.

- Serrations of appropriate $\lambda / A$ ratio show a delayed and smoothened entry in the instability or stall region, what causes significant differences in the noise radiation when compared to the baseline case. This noise reduction, however, is dominated by aerodynamic features of the serrations such as a delayed stall effect. At more stable flow conditions aeroacoustic effects such as decorrelation and incoherence effects come into play.

- Analysis of the separated noise reduction components in terms of tonal, broadband, BPF, low-frequency and total noise reduction revealed that at low incoming turbulence intensity, the reduction of tonal effects up to 2 $\mathrm{kHz}$ poses the main effect of the serrations whereas at elevated levels of turbulence the broadband and lowfrequency noise reductions becomes more and more dominant.

- The average noise reduction capability scales with the level of incoming turbulence though it also shows some grid-specific characteristics such as an increased noise reduction at minimum flow values for the lowest tested turbulence intensity. 
- The tested double-amplitudes show small improvements in terms of aerodynamics but no or even negative effects in terms of noise reduction compared to the reference serrations. Nevertheless, double-amplitude serrations remain a design for efficiently reduction leading edge noise.

- Testing serrations of variable amplitudes and wavelengths along the span indicates that the main noise reduction as well as aerodynamic effects occur in the outer regions of the fan blades close to the blade tip. Thus, maximising the effective surface close to hub leads to only small differences in aeroacoustic and aerodynamic efficiency.

\section{Acknowledgments}

The authors gratefully acknowledge the support by B.Eng. Nina Maimuna Balde from the University of Applied Sciences Duesseldorf.

\section{References}

${ }^{1}$ Biedermann, T. M., "Statistical-Empirical Modelling of Aerofoil Noise and Performance Subjected to Leading Edge Serrations," Internoise, Vol. 2016, 2016.

${ }^{2}$ Biedermann, T. M., Chong, T. P., Kameier, F., and Paschereit, C. O., "Statistical-Empirical Modelling of Airfoil Noise Subjected to Leading Edge Serrations," AIAA Journal, Volume 55, issue 9, 2017, pp. 3128-3142.

${ }^{3}$ Chaitanya, P., Narayanan, S., Joseph, P., and Kim, J. W., "Leading edge serration geometries for significantly enhanced leading edge noise reductions," 22nd AIAA/CEAS Aeroacoustics Conference, 2016.

${ }^{4}$ Chong, T. P., Vathylakis, A., McEwen, A., Kemsley, F., Muhammad, C., et al., "Aeroacoustic and Aerodynamic Performances of an Aerofoil Subjected to Sinusoidal Leading Edges," 2015.

${ }^{5}$ Biedermann, T., Chong, T. P., and Kameier, F., "Statistical-Empirical Modelling of Aerofoil Noise Subjected to Leading Edge Serrations and Aerodynamic Identification of Noise Reduction Mechanisms," 22nd AIAA/CEAS Aeroacoustics Conference, 2016.

${ }^{6}$ Biedermann, T., Kameier, F., Koster, O., Schreiber, D., Chong, T. P., et al., "Polyoptimisation of the Aerodynamic and Aeroacoustic Performance of Aerofoils with Serrated Leading Edges," 23rd AIAA/CEAS Aeroacoustics Conference, 2017.

${ }^{7}$ Moreau, S., Roger, M., and Christophe, J., "Flow Features and Self-Noise of Airfoils Near Stall or in Stall," 15th AIAA/CEAS Aeroacoustics Conference, 2009.

${ }^{8}$ Zenger, F., Renz, A., and Becker, S., "Experimental Investigation of Sound Reduction by Leading Edge Serrations in Axial Fans," 23rd AIAA/CEAS Aeroacoustics Conference, 2017.

${ }^{9}$ Krömer, F., and Becker, S., "Reduzierung der Schallemissionen von Axialventilatoren durch Vorderkantenmanipulationen," 44. Jahrestagung für Akustik DAGA, 2018.

${ }^{10}$ Corsini, A., Delibra, G., and Sheard, A. G., "Leading Edge Bumps in Ventilation Fans," Volume 4: Ceramics; Concentrating Solar Power Plants; Controls, Diagnostics and Instrumentation; Education; Electric Power; Fans and Blowers, ASME, 2013, V004T10A007.

${ }^{11}$ ISO, "Acoustics - Determination of sound power radiated into a duct by fans and other air-moving devices In-duct method (ISO 5136:2003)," No. 5136, 2009.

${ }^{12}$ ISO, "Industrial fans - Performance testing using standardized airways (ISO 5801:2007),” No. 5801, 2008.

${ }^{13}$ Carolus, T., Ventilatoren, Vieweg+Teubner Verlag, Wiesbaden, 2013.

${ }^{14}$ Carolus, T. H., and Starzmann, R., "An Aerodynamic Design Methodology for Low Pressure Axial Fans With Integrated Airfoil Polar Prediction," Volume 4: Cycle Innovations; Fans and Blowers; Industrial and Cogeneration; Manufacturing Materials and Metallurgy; Marine; Oil and Gas Applications, ASME, 2011, pp. 335-342.

${ }^{15}$ Chaitanya, P., Narayanan, S., Joseph, P., Vanderwel, C., Kim, J. W., et al., "Broadband noise reduction through leading edge serrations on realistic aerofoils," 2015.

${ }^{16}$ Chong, T. P., Joseph, P. F., and Gruber, M., "Airfoil self noise reduction by non-flat plate type trailing edge serrations," Applied Acoustics, Vol. 74, No. 4, 2013, pp. 607-613.

${ }^{17}$ Amiet, R. K., "Noise Produced by Turbulent Flow into a Propeller or Helicopter Rotor," AIAA Journal, Vol. 15, No. 3, 1977, pp. 307-308.

${ }^{18}$ Reese, H., Carolus, T., and Kato, C., "Numerical Prediction of the Aeroacoustic Sound Sources in a Low Pressure Axial Fan with Inflow Distortion," Fan Noise 2007, 2007.

${ }^{19}$ Wojno, J. P., Mueller, T. J., and Blake, W. K., “Turbulence Ingestion Noise, Part 2: Rotor Aeroacoustic Response to Grid-Generated Turbulence," AIAA Journal, Vol. 40, No. 1, 2002, pp. 26-32. 
${ }^{20}$ Laws, E. M., and Livesey, J. L., "Flow Through Screens," Annual Review of Fluid Mechanics, Vol. 10, No. 1, 1978, pp. 247-266.

${ }^{21}$ Biedermann, T., Kameier, F., and Paschereit, O., "Optimised Test Rig for Measurement of Aerodynamic and Aeroacoustic Performance of Leading Edge Serrations in Low-Speed Fan Application," Proceedings of ASME Turbo Expo 2018, 2018.

${ }^{22}$ Kim, J. W., Haeri, S., and Joseph, P. F., "On the reduction of aerofoil-turbulence interaction noise associated with wavy leading edges,” Journal of Fluid Mechanics, Vol. 792, 2016, pp. 526-552.

${ }^{23}$ Chong, T.P., Biedermann, T.M., Koster, O., and Hasheminejad, S.M., "Reduction of Aerofoil Trailing Edge Noise by Leading Edge Serration," 24th AIAA/CEAS Aeroacoustics Conference, 2018.

${ }^{24}$ Hansen, K., Kelso, R., and Doolan, C., "Reduction of Flow Induced Tonal Noise Through Leading Edge Tubercle Modifications,".

${ }^{25}$ Turner, J., Kim, J. W., Paruchuri, C. C., and Joseph, P., "Towards Understanding Aerofoils with DualFrequency Wavy Leading Edges Interacting with Vortical Disturbances," 22st AIAA/CEAS Aeroacoustics Conference, 2016. 